\title{
Theory and Practice in Bioethics
}

\author{
Graeme T. Laurie ${ }^{1}$
}

Published online: 25 November 2021

() National University of Singapore and Springer Nature Singapore Pte Ltd. 2021

We welcome readers to the new schedule of publication for the Asian Bioethics Review. Henceforth, issues will appear in January, April, July, and October of each year. The theme of this first issue of 2022 is interconnections between theory and practice. Alone and in combination, the contributions demonstrate the striking symbiotic relationship that exists in bioethics between normative arguments and theories about how the world could be better and the lived experiences of practitioners, patients, and citizens at profound moments in the human condition, most notably when life begins and when it ends.

The issue opens with a letter from members of the Permanent Medical Board for abortion beyond 20 weeks of gestation from the Post Graduate Institute of Medical Education and Research (PGIMER) in Chandigarh, India. The letter outlines the key provisions of the new law in India that came into force on 25 March 2021 and which has been heralded by the World Health Organization (2021) as a 'historic move to provide universal access reproductive health services'. The Medical Termination of Pregnancy (MTP) Amendment Act 2021 replaces a statute that had been on the books for 50 years, and - significantly — the new law now allows termination beyond the previous time limit of 20 weeks, up to 24 weeks in cases of rape and substantial foetal abnormalities (and sometimes beyond in specific circumstances). Building on an earlier article in this journal by Sasi (2019) that outlined the nature of the extensive debate in India on access to later term abortion, the letter welcomes the recent reforms while also acknowledging that wider systemic concerns remain such as the perpetuation of medical power over women and the real challenges of proof and timing when the reproductive health system comes up against the criminal justice system. These are stubborn problems in many countries of the world that continue to obstruct or deny access to health services to millions of women. This latest practical reform in India will contribute to the on-going debates on which bioethics has much to contribute.

The first original article of this issue from Yozwiak, McGuire, and Aultman [https://link.springer.com/article/10.1007/s41649-021-00184-0] is the second of two linked papers, the first having been published in the December 2021 issue of

Graeme T. Laurie

graeme.laurie@ed.ac.uk

1 Edinburgh Law School, The University of Edinburgh, Edinburgh, UK 
this journal (McGuire et al. 2021). The topic is the mental health of refugees during the COVID-19 pandemic, most notably concerning the experiences of Nepalispeaking Bhutanese refugees in the United States. While the first paper provided a qualitative systematic literature review of the experiences of refugee populations going through resettlement processes and which led to a theoretical social justice framework that incorporated specific social determinants impacting mental health outlined in that paper, this second paper lays out a call to action in communities in three key areas, identifying and tackling real barriers to social justice measures revealed by the research. The joint papers are geared towards informing real change for future practice.

Continuing the theme of theory and practice, the second and third original articles address key theoretical features of the debates about abortion and the female body that are raised by the very practical reforms outlined at the beginning of this issue. Thus, for example, Nisha's article on the medicalisation of the female body and motherhood [https://link.springer.com/article/10.1007/s41649-021-00185-z] uses the lenses of biological determinism and phenomenological existentialism to challenge medically supported perspectives on the female body that are informed by, and which in turn inform, socio-cultural constructs of women that are both limited and profoundly limiting. The author advocates for a de-medicalised model of medicine that better captures the true meaning of the maternal body and self. These arguments can be contrasted starkly with the provisions of the new Indian law, outlined above, that requires the assent of two medical practitioners before women can access essential reproductive health services.

Demonstrating the contribution of robust theory and critical analysis, the article by Simkulet [https://link.springer.com/article/10.1007/s41649-021-00189-9] offers important insights as to why inconsistency arguments in philosophy are morally significant. Against the backdrop of contributions from opponents of abortion, the author takes up recent debates about the relevance - or otherwise - of the failure of opponents of abortion to address and deal with instances of spontaneous abortion and the creation of surplus embryos from IVF as part of a coherent ethical frame of analysis for their position. The author argues that challenges of inconsistency matter very much and seeks to demonstrate why this is so.

The following two articles in this issue concern the role of bioethics at the opposite end of the spectrum of life. Each in their own way illustrates how key conceptual understandings from bioethics can inform the very practical matters of decisionmaking and care at the end of life, particularly as these affect practitioners. Asagumo [https://link.springer.com/article/10.1007/s41649-021-00191-1] highlights tensions within Japanese culture and medical practice that contrast the well-recognised principle of respect for individual autonomy relating to medical care with the very strong reluctance to respect refusals of treatment that will likely result in death. The paper details the legal and social context in which medical practitioners operate and which tends to promote interpretations of patients' wishes in ways that will avoid decisions about ceasing treatment if this will result in death. As a way to reconcile the putative tension between individual autonomy and societal values, the author posits that a suitably constructed concept of relational autonomy might go some way to resolving tensions at this crossroads of theory and practice. 
The paper by Chan et al. [https://link.springer.com/article/10.1007/s41649-02100192-0] provides further insights to the experiences of practitioners dealing with patients and decisions at the end of life. Here, the setting is the ICU and the particularly acute circumstances brought about by the COVID-19 pandemic. Having presented data about physicians' impressions and the impacts of working in ICU, the authors adopt Radha Krishna's Ring Theory of Personhood and apply this to the findings to provide insights into specific needs for support on a personal and organisational level. The argument is made that from this theory a valuable and practical assessment tool can be developed for personalised, tailored, and long-term support.

The final paper of this issue picks up a strong theme through recent issues of the journal, namely, the insidious presence and effects of cultural imperialism in matters of human health and its protection. However, the particular focus of the article by Muyskens [https://link.springer.com/article/10.1007/s41649-021-00190-2] is the human right to health. The paper involves an examination of the ways in which this universal right interacts with human cultures in the pursuit of global health justice and as against the threat of cultural imperialism. The resulting contribution is twofold: the article both demonstrates how cultural imperialism is a very real and constant moral hazard, and it offers strategies to think about the human right to health in ways that can reduce the threats and embolden the right as a tool of both practical and political import.

\section{References}

McGuire, Tanner, Daniel Yozwiak, and Julie M. Aultman. 2021. Impact of a Pandemic on Resettled Bhutanese Refugees' Mental Health. Asian Bioethics Review 13 (4): 375-399. https://doi.org/10.1007/ s41649-021-00183-1.

Sasi, Aiswarya. 2019. Ethical Issues Concerning Legislation in Late-Term Abortions in India. Asian Bioethics Review 11 (4): 367-376. https://doi.org/10.1007/s41649-019-00105-2.

World Health Organization. 2021. India's Amended Law Makes Abortion Safer and More Accessible. World Health Organization, 13 April 2021. Accessed 26 October 2021. https://www.who.int/india/ news/detail/13-04-2021-india-s-amended-law-makes-abortion-safer-and-more-accessible.

Publisher's Note Springer Nature remains neutral with regard to jurisdictional claims in published maps and institutional affiliations. 